\title{
Farklı antiseptik taşıyıcı ve kalsiyum hidroksit kombinasyonlarının doku çözücü etkinliğinin incelenmesi
}

\author{
Makbule Bilge Akbulut $^{\alpha}$, Mehmet Burak Güneşer ${ }^{\beta}$, Ayçe Ünverdi Eldeniz ${ }^{\gamma}$
}

Selcuk Dent J, 2017; 4: 1-5

Basvuru Tarihi: 11 Aralık 2016 Yayına Kabul Tarihi: 23 Ocak 2017

Öz

Farklı antiseptik taşıyıcı ve kalsiyum hidroksit kombinasyonlarının doku çözücü etkinliğinin incelenmesi

Amaç: $\mathrm{Bu}$ in vitro çalışmanın amacı farklı antiseptik taşıyıcı kalsiyum hidroksit $(\mathrm{KH})$ kombinasyonlarının sığır dokusu üzerindeki doku çözücü etkinliğini değerlendirmektir.

Gereç ve Yöntemler: Yeni kesilmiş sığır damağından doku örnekleri elde edildi. Benzer şekilli 170 adet doku örneği hazırlandı. Örnekler önceden tartılan mikrosantrifüj tüplerine yerleştirildi ve $55^{\circ} \mathrm{C}$ 'de 18 saat kurutuldu. Başlangıç ağırlıkları hassas terazi ile ölçüldü. $\mathrm{KH}$ tozu; gliserin - distile su karıșımı (7:1), Octenisept, Savlex, Klorheksidin (CHX) ya da sodyum hipoklorit $(\mathrm{NaOCl})$ ile karıștırıldı. Hazırlanan kanal içi medikamentler (KM), doku örnekleri içeren tüplere yerleştirildi ve 20 sn vortekslendi. Örnekler $37^{\circ} \mathrm{C}$ 'de $\% 100$ nemlilikte $\mathrm{KH}+$ gliserin-distile su, $\mathrm{KH}+$ Octenisept, $\mathrm{KH}+$ Savlex, $\mathrm{KH}+\mathrm{CHX}$ ya da $\mathrm{KH}+\mathrm{NaOCl}$ karışımlarının içerisinde, 1,3 ve 7 gün boyunca inkübe edildi, sonrasında $5 \mathrm{ml}$ distile su ile yıkandı. Örnekler tekrar $55^{\circ} \mathrm{C}$ 'de 18 saat kurutuldu ve son kuru ağırlıkları ölçüldü. Doku ağırlık kaybı yüzdesi hesaplandı ve veriler tek yönlü varyans analizi ve Tukey testleri kullanılarak analiz edildi.

Bulgular: $\mathrm{KH}+\mathrm{CHX}, \mathrm{KH}+\mathrm{NaOCl}$ ve $\mathrm{KH}+$ Octenisept grupları, $\mathrm{KH}+$ Savlex ve $\mathrm{KH}+$ gliserin-distile su gruplarına göre sığır damak dokusunu daha iyi çözmüştür $(P<0.05)$. $\mathrm{KH}+$ Octenisept karışımı 3 günlük inkübasyon periyodunda daha iyi doku çözücü etkinlik sergilemiştir.

Sonuç: $\mathrm{KH}$ 'yi \%5.25'lik NaOCl, \%2'lik $\mathrm{CHX}$ ya da Octenisept ile karıștırarak kullanmak pulpa artıklarını çözmek bakımından klinisyenler için daha avantajlı olacaktır.

\section{ANAHTAR KELIMELER}

Antiseptik, endodonti, kalsiyum hidroksit, kanal-içi medikament

Endodontik tedavinin başarılı olmasını etkileyen en önemli faktörlerden birisi mikroorganizmalardan arındırılmıs kök kanal sisteminin elde edilmesidir. Bu süreçte kök kanal içeriğinin mekanik olarak uzaklaştıııması önemlidir. Kök kanallarında, vital pulpa dokusu, nekrotik debris, mikroorganizmalar ve etkilenmiş dentin bulunmaktadır. ${ }^{1}$ Kemomekanik

\section{ABSTRACT}

Tissue dissolving capacity of various new antiseptic vehicle calcium hydroxide combinations

Background: The aim of this in vitro study was to evaluate tissue dissolution ability of various new antiseptic vehicle and calcium hydroxide combinations on bovine tissue.

Methods: Tissue specimens were obtained from freshly dissected bovine palates. One hundred and seventy tissue samples of similar form were prepared. Specimens were placed in preweighted $1.5 \mathrm{ml}$ microcentrifuge tubes and desiccated at $55^{\circ} \mathrm{C}$ for 18 hour. Initial dry weights were measured with an analytic balance. Calciumhydroxide powder were mixed as follows in Group 1: Glycerin with distilled water (7:1 ratio); Group 2: Octenisept; Group 3: Savlex; Group 4: $2 \%$ Chlorhexidine (CHX); or Group 5: $\mathrm{NaOCl}$ and filled into the tubes containing the tissues and vortexed for 20 seconds. Specimens were incubated at $37^{\circ} \mathrm{C}$ in $100 \%$ humidity for 1,3 and 7 days and then were carefully rinsed with $5 \mathrm{~mL}$ distilled water and blotted dry. Samples were desiccated at $55^{\circ} \mathrm{C}$ for 18 hour and final dry weights were measured. Percentage of tissue weight loss was calculated and statistically analyzed by using one way analysis of variance and Tukey tests.

Results: Mixing calcium hydroxide with chlorhexidine, $5.25 \%$ $\mathrm{NaOCl}$ and Octenisept dissolved the tissue more effectively than calcium hydroxide and Savlex and glycerin/water mixtures $(P<0.05)$. Calcium hydroxide and Octenisept mixture demonstrated better tissue dissolving properties after 3 days of incubation.

Conclusion: Mixing calcium hydroxide with $5.25 \% \mathrm{NaOCl}, 2 \% \mathrm{CHX}$ or Octenisept could be more advantageous for the clinicians in dissolving pulp tissue remnants.

\section{KEYWORDS}

Antiseptics, endodontics, calcium hydroxide, root canal medicaments

preparasyon iyi bir kanal temizliği için her zaman yeterl olamamakta ilave olarak kanal içi medikament (KM) uygulamasına intiyaç duyulmaktadır. Hem kemomekanik preparasyon hem de KM uygulanması doku artıklarında fiziksel ve kimyasal değişimlere yol açmakta ve bu doku artıklarının kanaldan uzaklaştırımasını kolaylaştırmaktadır.

\footnotetext{
${ }^{\alpha}$ Necmettin Erbakan Üniversitesi Diş Hekimliği Fakültesi Endodonti Anabilim Dalı, Konya

$\beta$ Bezmialem Vakıf Üniversitesi Diş Hekimliği Fakültesi Endodonti Anabilim Dalı, İstanbul

${ }^{\gamma}$ Selçuk Üniversitesi Diş Hekimliği Fakültesi Endodonti Anabilim Dalı, Konya
} 
En yaygın kullanılan $\mathrm{KM}$ olan kalsiyum hidroksit $(\mathrm{KH})$; güçlü antimikrobiyal etkinlik sergileyebilme, doku çözebilme ve aynı zamanda sert doku oluşumunu indükleyebilme özelliklerine sahiptir. ${ }^{2}$ Bu özellikleri dolayısıyla da endodontide pek çok klinik uygulamada tercih edilmektedir. KH'nin doku çözücü etkinliği 1988 yılında yapılan bir araştırmada çalışılmış ve o araştırmada KH'nin nekrotik domuz kas dokusunu çözebildiği ve önceden $\mathrm{KH}$ uygulamasının NaOCl'nin doku çözücü etkinliğini arttırdığı gösterilmiştir. ${ }^{3}$ Diğer bir çalışmada ${ }^{4}, K H^{\prime}$ nin 7 gün boyunca uygulandığı kök kanallarında pulpa doku artıklarının oldukça azalmış olduğu ve kanal duvarlarında birtakım kalkosferitlerin bulunduğu gösterilmiştir.

$\mathrm{KH}$, bütün tipteki endodontik enfeksiyonlara karşı etkili değildir. Daha uzun süreli ve geniş spektrumlu antimikrobiyal etkinlik elde etmek için $\mathrm{KH}$ tozunun irrigasyon solüsyonlarılya karıştırılması önerilmiştir. ${ }^{5} \mathrm{KH}$ 'ye ilave edilen taşıyıcı, iyon çözünürlüğünün hızını etkilemesi bakımından önem taşımaktadır. ${ }^{6} \mathrm{KH}$-antiseptik taşıyıcı karışımları konvansiyonel KM'lerine nazaran daha iyi doku çözücü etkinliğe sahip olabilir.

$\mathrm{Bu}$ in vitro çalışmanın amacı farklı antiseptik taşıyıcı ve KH kombinasyonlarının sığır damak dokusu üzerindeki doku çözücü etkisini değerlendirmektir. $\mathrm{KH}$ ile karıştırımak üzere değerlendirilen antiseptik taşıyıcılar; gliserin distile su karışımı (7:1), oktenidin hidroklorit, \%2'lik klorheksidin glukonat (CHX), \%15'lik setrimit - \%1.5'luk klorheksidin karışımı ve $\% 5.25$ 'lik NaOCl'dir.

\section{GEREÇ VE YÖNTEM}

Bu çalışmada üç adet sığııın damak mukozası kullanıldı. Dokuları kullanılan bu hayvanlar yiyecek üretimi amacıyla kesilmiştir ve kesimden 4 saat sonra çalışmaya dâhil edilmiştir. Çalışma protokolüne göre hayvanlar canlı iken herhangi bir işleme tabi tutulmadığından ve ticari nedenlerle kesildiklerinden etik kurul onayına sunulmamıştır.

Tam kalınlık kesilen sığır damak mukozası bistüri ile $4 \times 4 \times 2 \mathrm{~mm}$ boyutlarında olacak şekilde ayrıldı. Aynı formdaki ve yaklaşık aynı ağırlıktaki 170 adet doku örneği kuru ağırlığı belirlemek amacıyla önceden tartılmış $1,5 \mathrm{~mL}$ hacmindeki mikrosantrifüj tüplerine yerleştirildi. Tüpler 55 ${ }^{\circ}$ 'ye ayarlanmış kurutma fırınında 18 saat bekletildi. Kurutma işlemi tamamlandıktan sonra doku örneklerinin başlangıç kuru ağırlığı bir hassas terazi (Sartorius CP2245, Gottingen, Almanya) kullanılarak ölçüldü. Örnekler 5 deney grubu $(n=30)$ ve 2 kontrol grubuna ayrıldı $(n=10)$. Doku örneklerinin üzerine uygulanmak üzere hazırlanan deney grupları aşağıdaki gibidir;

Grup 1: $\mathrm{KH}$ (Sultan Chemists, Englewood, $\mathrm{ABD}$ ) + gliserin distile su (7:1 oranında) ${ }^{7}$

Grup 2: KH + Octenisept (Octenisept, Schülke \& Mayr, Almanya)

Grup 3: KH + Savlex (Drogsan, Ankara, Türkiye)

Grup 4: $\mathrm{KH}+\% 2 \mathrm{CHX}$ (Drogsan, Ankara, Türkiye)

Grup 5: KH + \%5.25 NaOCl (Çağlayan Kimya, Konya, Türkiye)

Kontrol 1: Fizyolojik salin

Kontrol 2: Distile su

Hazırlanan KM'ler mikrosantrifüj tüplerine doku örneğinin yüzeyini tamamen kapatacak şekilde $(1000 \mathrm{mg})$ yerleştirildi ve dokuyla temasını arttırmak için tüpler 20 sn boyunca vortekslendi. Deney gruplarının doku örnekleri üç alt gruba ayrıldı $(n=10)$ ve örnekler $37^{\circ} \mathrm{C}$ 'de $\% 100$ nemlilikte 1,3 ve 7 gün boyunca desikatör içerisinde inkübe edildi. İnkübasyon süreci tamamlandıktan sonra doku örnekleri $5 \mathrm{~mL}$ distile su ile yıkandı ve kurutma kâğıdı ile kurulandı. Doku örnekleri tekrar 55 ${ }^{\circ} \mathrm{C}$ 'de 18 saat boyunca kurutuldu ve son kuru ağırlıkları hassas terazi yardımıyla ölçüldü. Aşağıdaki formül kullanılarak doku ağlık kaybının yüzdesi hesaplandı;

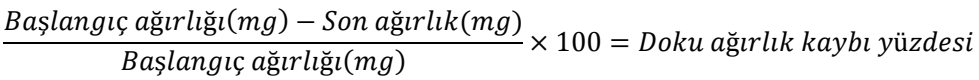

\section{İstatistiksel Analiz}

İstatistiksel analiz için IBM SPSS Statistics V19 (SPSS Inc, Chicago Illinois, $A B D$ ) programı kullanıldı. Veriler tek yönlü varyans analizi ve gruplar arası karşılaştırma için Tukey HSD testleri kullanılarak analiz edildi. İstatistiksel analiz, \%5 anlamlılık seviyesinde yapılmıştır.

\section{BULGULAR}

Kontrol grupları deney gruplarına göre anlamlı seviyede daha iyi doku çözücü etkinlik göstermiştir $(P<0.05)$ (Resim 1). Deney KM gruplarının doku çözücü etkinliği arasındaki fark anlamlı bulunmuştur $(\mathrm{P}=0.000)$. $\mathrm{KH}+\mathrm{CHX}, \mathrm{KH}+\mathrm{NaOCl}$ ve $\mathrm{KH}+$ Octenisept grupları arasında istatistiksel olarak anlamlı fark olmamakla birlikte bu gruplar; $\mathrm{KH}+$ Savlex ve $\mathrm{KH}+$ gliserin-distile su grupları ile karşılaştııılıklarında sığır damak dokusunu daha iyi çözmüştür $(P<0.05)$. $\mathrm{KH}+$ gliserin-distile su grubu ve $\mathrm{KH}+$ Savlex gruplarına maruz kalan doku örneklerinde ağırlık artışı gözlenmiştir. İnkübasyon süresinin değişmesi $\mathrm{KH}+$ Savlex ve $\mathrm{KH}+$ gliserin-distile su gruplarının doku üzerindeki fiziksel etkinliğini değiştirmemiştir (Tablo 1). $\mathrm{KH}+$ Octenisept karışımı 3 günlük inkübasyon sonrasında daha iyi doku çözücü etkinlik göstermiştir $(P<0.05)$. KH + $\mathrm{CHX}$ ve $\mathrm{KH}+\mathrm{NaOCl} \mathrm{KM}$ grupları 3 gün ve 7 gün inkübasyon periyodu sonrasında 1 gün ile karşılaştııılığında daha iyi doku çözmüştür $(P<0.05)$. 


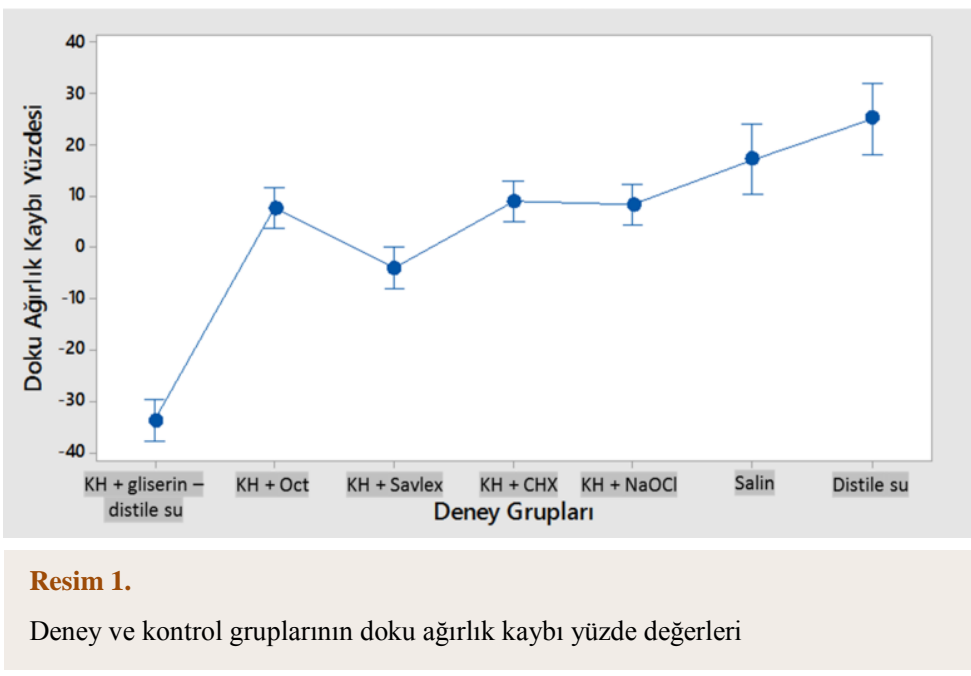

Tablo 1.

\section{Deney gruplarının inkübasyon sürelerine göre doku ağırlık kaybı yüzdesi ortalama ve standart sapma değerleri}

\begin{tabular}{|c|c|c|c|c|}
\hline Gruplar & 1 gün & 3 gün & 7 gün & p değeri \\
\hline $\begin{array}{l}\mathrm{KH}+ \\
\text { gliserin - } \\
\text { distile su }\end{array}$ & $-28,06 \pm 30,85^{\mathrm{a}}$ & $-39,40 \pm 16,24^{a}$ & $-33,77 \pm 11,63^{\mathrm{a}}$ & 0,499 \\
\hline $\begin{array}{l}\mathrm{KH}+ \\
\text { Octenisept }\end{array}$ & $0,411 \pm 2,329^{b}$ & $16,45 \pm 18,34^{\mathrm{a}}$ & $6,470 \pm 2,422^{a b}$ & $0,009^{*}$ \\
\hline $\mathrm{KH}+$ Savlex & $-2,85 \pm 4,47^{\mathrm{a}}$ & $-6,07 \pm 5,13^{\mathrm{a}}$ & $-3,55 \pm 6,21^{a}$ & 0,375 \\
\hline $\begin{array}{l}\mathrm{KH}+\% 2 \\
\mathrm{CHX}\end{array}$ & $4,51 \pm 4,43^{b}$ & $10,55 \pm 3,52^{\mathrm{a}}$ & $11,43 \pm 5,30^{\mathrm{a}}$ & $0,003^{\star}$ \\
\hline $\begin{array}{l}\mathrm{KH}+\% 5.25 \\
\mathrm{NaOCl}\end{array}$ & $4,21 \pm 3,29^{b}$ & $11,60 \pm 3,36^{\mathrm{a}}$ & $8,89 \pm 3,33^{\mathrm{a}}$ & $0,000^{*}$ \\
\hline
\end{tabular}

${ }^{*} P<0.05$

Farklı küçük harfler, deney grupları arasında istatistiksel olarak anlamlı fark olduğunu ifade eder.

\section{TARTIŞMA}

Bu çalışmada faklı antiseptik taşıyıcı ve $\mathrm{KH}$ karışımlarının sığır damak dokusu üzerindeki doku çözücü etkinliği değerlendirilmiştir. Literatürde çeşitli irrigasyon solüsyonlarının doku çözücü etkinliğini değerlendirmek için farklı doku örneklerinin kullanıldığı araştırmalar mevcuttur. Bu çalışmada diş pulpası yerine sığır damak dokusu tercih edilmiştir. Bunun sebebi hem sığır damak dokusuna ulaşılabilirliğin daha kolay olması hem de her bir örneğin yüzey alanı bakımından standardizasyonunun sağlanabilmesidir. ${ }^{8}$

Çalışmamızın bulgularına göre $\mathrm{KH}+$ gliserin-distile su ve $\mathrm{KH}+$ Savlex grupları doku ağırlık artışına sebep olmuştur. $\mathrm{Bu}$ kombinasyonların içeriğinde bulunan gliserin ve Savlex özellik olarak yağlı yapıda olan maddelerdir. Deney gruplarının hepsinde KM'leri uzaklaştırmak için eşit hacimde distile su kullanılmıştır. Kullanılan distile su dokunun yapısına nüfuz eden bu yağlı yapının uzaklaştıııması için yeterli gelememiş olabilir ve bu da sonuçlarımıza doku ağırık artışı olarak yansımış olabilir. Savlex solüsyonunun içerisinde bulunan setrimit yüzey aktif madde yani surfaktandır. Yüzey aktif maddeler çoğunlukla yüzey gerilimini azaltırlar. Yüzey gerilimi azaldığında, solüsyon ile dokunun temas yüzeyinin artması dolayısıyla doku çözme işlevinin de gelişmesi beklenmektedir. Nitekim daha önce yapılan bir çalışmada surfaktan eklenen NaOCl'nin sadece NaOCl'ye göre daha iyi doku çözücü özellik sergilediği gösterilmiştir. ${ }^{9}$ Yine Stojicic ve ark'nın ${ }^{10}$ çalışmasında surfaktan eklenen NaOCl'nin bütün sıcaklıklarda ve konsantrasyonlarda en etkin doku çözücü olduğu gösterilmiştir. Ancak, literatürde KH'nin Savlex ile kombinasyonunun doku çözme etkinliğini araştıran bir çalışma bulunmamaktadır. $\mathrm{KH}$ ile taşıyıcı olarak setrimiti kullanan çalışmalar bu karışımın antimikrobiyal özelliklerini incelemiştir. ${ }^{11}$ Doku çözücü etkinlik bakımından $\mathrm{NaOCl}$ ile sinerjistik etki gösteren surfaktan madde aynı etkiyi katı bir toz olan $\mathrm{KH}$ ile gösterememiş olabilir. Hem $\mathrm{KH}+$ gliserin -distile su grubu hem de $\mathrm{KH}+$ Savlex grupları doku çözme işlevi gerçekleştirememiş olup farklı inkübasyon süreleri de bu KM'lerin doku ağırlık artışını etkilememiştir.

$\mathrm{Bu}$ çalışmanın sonuçları $\mathrm{KH}+\mathrm{NaOCl}, \mathrm{KH}+$ Octenisept ve $\mathrm{KH}+\mathrm{CHX}$ gruplarının benzer doku çözücü özellik sergilediğini göstermiştir. $\mathrm{NaOCl}$ geniş spektrumlu antimikrobiyal özelliği, smear tabakasının organik kısmının oluşumunu engelleyebilmesi ve doku artıklarını çözebilmesi dolayısıyla temel irrigasyon solüsyonu olarak önerilmektedir. ${ }^{12} \mathrm{NaOCl}$ 'nin doku çözücü etkinliği daha önce yapılan çalışmalarla desteklenmiştir. ${ }^{8}$, ${ }^{10}$ Çalışmamızın bulgularını destekleyen Zehnder ve $\operatorname{ark}^{\prime}$ ın $^{13}$ çalışmasında $\mathrm{KH}$ ile $\mathrm{NaOCl}$ karışımının dört günlük inkübasyon sürecinde konvansiyonel $\mathrm{KH}$ preparatlarına (KH - salin) nazaran daha etkin doku çözdüğü gösterilmiştir. Çalışmamızda $\mathrm{KH}$ ile karıştırılan $\mathrm{NaOCl}$ \%5.25'liktir. Nitekim NaOCl'nin konsantrasyon artışının doku çözücülüğünü arttırdığı daha önce gösterilmiştir. ${ }^{10}$

Oktenidin hidroklorit, fenoksietanol ve saf su içeren Octenisept; yara dezenfektanı, deri yanıkları için antiseptik ve gargara olarak kullanılmaktadır. Octenisept iyi antimikrobiyal özelliği dolayısıyla endodontik irrigasyon solüsyonu olarak önerilmiştir. ${ }^{14}$ Octenisept'in irrigasyon solüsyonu olarak doku çözücü etkinliğini değerlendiren araştırma sayısı oldukça azdır ve yapılan çalışmalarda Octenisept'in doku 
çözmede yetersiz kaldığı gösterilmiştir. ${ }^{15,16}$ Nitekim esasen yara dezenfektanı olarak kullanılan bu solüsyondan iyi doku çözücü özellik beklenmemektedir. $\mathrm{KH}+$ Octenisept grubu bu çalışmada iyi doku çözücü etkinlik sergilemiştir. Tek başına bu özelliği gösteremeyen Octenisept'in $\mathrm{KH}$ ile bir araya geldiğinde aktive olması iki materyalin kimyasal olarak etkileşim gösterdiği anlamına gelebilir. Yazarların bildiği kadarıyla literatürde Octenisept'i KH'nin taşıyıcısı olarak kullanan bir araştırma bulunmamaktadır. Dolayısıyla elimizdeki veriler bu sonucu açıklamak için şimdilik yetersiz kalmaktadır.

Geniş spektrumlu antimikrobiyal bir ajan olan $\mathrm{CHX}$ hem irrigasyon solüsyonu hem de KM olarak tercih edilmektedir. \%0.5'lik CHX ile kombine edilen $\mathrm{KH}$ 'nin C. albicans'ın eliminasyonunda başarılı olduğu gösterilmiş ve bu kombinasyon alternatif bir KM olarak önerilmiştir. ${ }^{5}$ Çalışmamızda $\mathrm{KH}+\mathrm{CHX}$ grubunun iyi doku çözücü etkinlik sergilediği gösterilmiştir. $\mathrm{KH}$ tozu ile irrigasyon solüsyonu karışımlarının fiziksel ve kimyasal özelliklerini inceleyen bir çalışmada KH'ye klorheksidin ilavesinin temas açısını azalttığı ve medikamentin kök kanalında ıslanabilirliğini arttırdığı gösterilmiştir. ${ }^{17} \mathrm{Bu}$ özelliği dolayısıyla $\mathrm{KH}+\mathrm{CHX}$ karışımı sığı damak dokusuna daha iyi penetre olmuş ve doku ağırlık kaybını arttıracak yönde etki göstermiş olabilir. Yapılan diğer bir çalışmada da $\mathrm{KH}$ klorheksidin kombinasyonunun doku çözücü etkinlik gösterdiği bulunmuştur. ${ }^{13}$

$\mathrm{Bu}$ çalışmanın bulguları $\mathrm{KH}+\mathrm{NaOCl}, \mathrm{KH}+$ Octenisept ve $\mathrm{KH}+\mathrm{CHX}$ gruplarının doku çözücü etkinliği kontrol gruplarıyla karşılaştıııldığında daha az olduğunu göstermektedir. Kontrol grupları olan distile su ve fizyolojik salin sıvı oldukları için daha katı kıvamda olan bu KM'lerden daha iyi doku çözücü aktivite göstermesi beklenen bir durumdur. $\mathrm{KH}+$ Octenisept grubunun 3 günlük inkübasyon sürecinde, $\mathrm{KH}+\mathrm{NaOCl}$ ve $\mathrm{KH}+$ $\mathrm{CHX}$ gruplarının ise 3 ve 7 günlük inkübasyon süreçlerinde en iyi doku çözücü etkinliği sergilemiştir. Daha uzun süre temas zamanının materyalin doku çözücülüğünü geliştirdiği bu çalışma ile desteklenmiştir. ${ }^{18}$

Sonuç olarak bu bulgular KH'yi $\mathrm{NaOCl}$, Octenisept ve klorheksidin ile karıştırmanın doku çözücü etkinlik bakımından avantajı olduğunu göstermektedir. Uygulama süresi, KM'lerin doku çözücülüğü üzerinde önemli etkiye sahiptir.

\section{Teşekkür}

Yazarlar Doç. Dr. Serhan Akman'a istatistiksel analizdeki katkılarından dolayı teşekkür eder. 


\section{KAYNAKLAR}

1. Schilder $\mathrm{H}$. Cleaning and shaping the root canal. Dent Clin North Am 1974;18:269-96.

2. Nerwich A, Figdor D, Messer HH. Ph changes in root dentin over a 4-week period following root canal dressing with calcium hydroxide. J Endod 1993;19(6):302-6.

3. Hasselgren G, Olsson B, Cvek M. Effects of calcium hydroxide and sodium hypochlorite on the dissolution of necrotic porcine muscle tissue. J Endod 1988;14(3):125-7.

4. Wadachi R, Araki K, Suda H. Effect of calcium hydroxide on the dissolution of soft tissue on the root canal wall. J Endod 1998; 24(5): 326-30.

5. Waltimo TMT, Orstavik D, Siren EK, Haapasalo MPP. In vitro susceptibility of candida albicans to four disinfectants and their combinations. Int Endod J 1999;32(6):421-9.

6. Fava L, Saunders W. Calcium hydroxide pastes: Classification and clinical indications. Int Endod J 1999;32(4):257-82.

7. Alacam T, Yoldas HO, Gulen O. Dentin penetration of 2 calcium hydroxide combinations. Oral Surg Oral Med Oral Pathol Oral Radiol Endod 1998;86(4):469-72.

8. Türkün $M$, Cengiz T. The effects of sodium hypochlorite and calcium hydroxide on tissue dissolution and root canal cleanliness. Int Endod $\mathrm{J}$ 1997;30(5):335-42.

9. Almeida LHSd, Gomes APN, Giardino L, Souza EM, Pappen FG. Pulp tissue dissolution capacity of sodium hypochlorite combined with cetrimide and polypropylene glycol. Braz Dent J 2013; 24(5):477-81.

10.Stojicic S, Zivkovic S, Qian W, Zhang $H$, Haapasalo M. Tissue dissolution by sodium hypochlorite: Effect of concentration, temperature, agitation, and surfactant. J Endod 2010; 36(9): 1558-62.

11. Turk BT, Sen BH, Ozturk T. In vitro antimicrobial activity of calcium hydroxide mixed with different vehicles against enterococcus faecalis and candida albicans. Oral Surg Oral Med Oral Pathol Oral Radiol Endod 2009;108(2):297-301.

12.Zehnder M. Root canal irrigants. J Endod 2006; 32(5):389-98.

13.Zehnder M, Grawehr M, Hasselgren G, Waltimo T. Tissue-dissolution capacity and dentindisinfecting potential of calcium hydroxide mixed with irrigating solutions. Oral Surg Oral Med Oral Pathol Oral Radiol Endod 2003;96(5):608-13.
14.Eldeniz AU, Guneser MB, Akbulut MB Comparative antifungal efficacy of light-activated disinfection and octenidine hydrochloride with contemporary endodontic irrigants. Lasers Med Sci 2015; 30(2):669-75.

15.Arslan D, Guneser MB, Kustarci A, Er K, Siso SH. Pulp tissue dissolution capacity of qmix 2in1 irrigation solution. Eur J Dent 2015;9(3):423-7.

16.Güneşer MB, Akbulut MB, Ünverdi EA. Oktenidin hidrokloridin doku çözücü etkisinin geleneksel İrrigasyon solüsyonlarıyla karşılaştırılması. Turkiye Klinikleri J Dental Sci 2015;21(2):117-22.

17.Basrani B, Ghanem A, Tjäderhane L. Physical and chemical properties of chlorhexidine and calcium hydroxide-containing medications. J Endod 2004; $30(6): 413-7$.

18.Christensen CE, McNeal SF, Eleazer P. Effect of lowering the ph of sodium hypochlorite on dissolving tissue in vitro. J Endod 2008;34(4):44952.

Yazışma Adresi:

Yrd.Doç.Dr.Makbule Bilge AKBULUT

Necmettin Erbakan Üniversitesi

Diş Hekimliği Fakültesi

Endodonti AD

Konya, Türkiye

Tel : +903322200026

Faks : +90 3322200045

E-mail:dt.bilge@yahoo.com 